\title{
Richard Payne. "The Making of Turan: The Fall and Transformation of the Iranian East in Late Antiquity"
}

\section{Rika Gyselen}

\section{(2) OpenEdition}

Journals

Édition électronique

URL : http://journals.openedition.org/abstractairanica/47467

DOI : 10.4000/abstractairanica.47467

ISBN : 1961-960X

ISSN : 1961-960X

Éditeur :

CNRS (UMR 7528 Mondes iraniens et indiens), Éditions de l'IFRI

\section{Référence électronique}

Rika Gyselen, «Richard Payne. "The Making of Turan: The Fall and Transformation of the Iranian East in Late Antiquity" », Abstracta Iranica [En ligne], Volume 37-38-39 | 2018, document 81, mis en ligne le 30 décembre 2018, consulté le 02 octobre 2020. URL : http://journals.openedition.org/ abstractairanica/47467 ; DOI : https://doi.org/10.4000/abstractairanica.47467

Ce document a été généré automatiquement le 2 octobre 2020.

Tous droits réservés 


\title{
Richard Payne. "The Making of Turan: The Fall and Transformation of the Iranian East in Late Antiquity"
}

\author{
Rika Gyselen
}

\section{RÉFÉRENCE}

Richard Payne. "The Making of Turan: The Fall and Transformation of the Iranian East in Late Antiquity", Journal of Late Antiquity, Volume 9, Number 1, Spring 2016, p. 4-41

1 Le terme Turan se réfère ici à la culture politique hybride qui se développe à l'est et audelà du nord-est iranien à la suite des contacts entre l'empire sassanide et des peuples nomades comme les Huns et les Turks, et non au nom géographique Tūrān, une région dans le sud de l'est iranien. Dans la littérature iranienne, en particulier chez Ferdowsi au Xe siècle, Turan, région dont les élites politiques étaient nomades, est l'antithèse de l'Iran où les populations sont sédentaires. Dans la littérature cette opposition remonte à des origines mythiques.

2 L'auteur évoque les causes de la transformation des pays de l'Europe de l'ouest sous la domination de Rome et ceux du nord-est iranien, en particulier l'Asie centrale.

«La conquête de l'est iranien ». Sous ce titre est traité, entre autres, le cadre historique dans lequel ont lieu au IVe siècle les premiers échanges et confrontations entre l'Iran sassanide et les nomades qui envahissent le nord-est et l'est iraniens. «Institutions iraniennes adoptées et adaptées par les Huns et les Turks ».

On peut s'étonner que le terme 'sassanide' semble soigneusement évité et a été très souvent remplacé par 'iranien'. Pourquoi, par exemple, parler de "post-Iranian regimes » alors qu'il s'agit de toute évidence de « post-Sasanian regimes » (p. 4) ? 
6 Comme le souligne l'auteur, sans la numismatique, l'histoire des Huns et des Turks serait impossible à reconstituer. Un apport conséquent est aussi fourni par la publication des 'documents bactriens' qui a permis de connaître l'histoire d'une dynastie locale, située un peu au sud de Balkh, et de voir comment elle s'est adaptée, du IIIe jusqu'au début du VIIIe siècle, aux différentes puissances militaires qui se rendent maîtres de cette région.

7 D'une façon générale les traditions institutionnelles sassanides et nomades se fondent dans un système unique qui sera ensuite adopté par les populations des steppes.

8 « Aristocraties nomades et leur stratégie de se distinguer ». Plusieurs paragraphes sont consacrés à la conception d'une identité ethnique dans lesquels l'auteur présente les 'Huns' comme des groupes ethniques variés contrairement aux Turks. Il souligne aussi les différentes façons dont les éléments sassanides ont été intégrés par les uns et les autres.

9 «Les Turaniens ». Dans les textes zoroastriens les antagonistes des iraniens « Ērān » sont le peuple historico-mythique des xyōn. Dans les narrations de la cour sassanide du Ve siècle, les rois nomades sont désignés comme «Tūrān », descendant de Tūr, fils de Fereydūn qui lui avait confié un tiers du royaume êr "iranien ». L'auteur soulève la récupération du héros mythique Rustam qui, en épousant la fille d'un roi idolâtre de Kabul, devient un symbole d'union entre Ērān et Tūrān. Il ne fait aucun doute que les Turks n'ont pas seulement refaçonné l'histoire mythologique sassanide, mais se sont appropriés aussi les concepts et les symboles politiques sassanides.

\section{AUTEURS}

\section{RIKA GYSELEN}

CNRS, Mondes iranien et indien 